\title{
PEMBELAJARAN GENERATIF DENGAN PENDEKATAN KONTEKSTUAL BERBASIS DARING UNTUK MENINGKATKAN SOFT SKILL SISWA
}

Yennia), Rahayu Cahyani ${ }^{\text {b) }}$

a,b Universitas Muhammadiyah Tangerang, Banten

Corresponding Author : yenni_aan@@yahoo.co.id a)

Ayu42019@gmail.com ${ }^{\text {b) }}$

\begin{tabular}{lc}
\hline \multicolumn{2}{c}{ Article Info } \\
\hline Keywords : & soft skill, \\
Generative & Learning, \\
Contextual & Approach, \\
Online Based &
\end{tabular}

The purpose of this study was to determine whether there was an increase in soft skills between students who were given a generative learning model with a contextual approach, and students who were given conventional methods. This study uses a quasi-experimental method with the nonequvalent control group design type. The population in this study were students of VIII MTs Insan Kreasi. The research sampel cansisted of 65 students, with 34 students in the experimental class and 31 students in the control class. The data collection technique used the simple random sampling technique. The results of this study indicate that there are differences in the improvement of students' soft skills between students who use generative learning model with a contextual approach, and students who use conventional learning models. This is besad on the result of hypothesis testing using the t-test, that is, there is a significant difference between the students" posttest soft skill scores in the experimental class and the control class. The result then carried out the $n$-gain test obtained the value of the experimental class > the value of the control class, namely $0.2557>0.0314$, so there was an increase in the soft skill of students in the experimental class and the control class.

Kata Kunci: Soft skill, Tujuan penelitian ini adalah untuk mengetahui apakah terdapat Pembelajaran Generatif, peningkatan soft skill antara siswa yang diberi model Kontekstual, dalam pembelajaran generatif dengan pendekatan kontekstual, dan jaringan siswa yang diberi metode konvensional. Penelitian ini menggunakan metode Quasi eksperiment dengan jenis Nonequivalent Control Group Design. Populasi dalam penelitian 
ini adalah siswa kelas VIII MTs Insan Kreasi. Sampel berjumlah 65 siswa, dengan 34 siswa pada grup eksperimen dan 31 siswa pada grup kontrol. Teknik pengambilan data menggunakan acak kelas. Hasil penelitian menunjukkan bahwa terdapat perbedaan peningkatan soft skill siswa antara siswa yang menggunakan model pembelajaran generatif dengan pendekatan kontekstual, dan siswa yang menggunakan model pembelajaran konvensional. Hal tersebut berdasarkan hasil uji hipotesis dengan menggunakan uji-t diperoleh $t_{\text {hitung }}>t_{\text {tabel }}$ yaitu $(2,7705>1,669)$, maka terdapat perbedaan yang signifikan antara skor postest soft skill siswa grup eksperimen dan siswa grup kontrol. Hasil uji n-gain diperoleh nilai grup eksperimen > nilai grup kontrol yaitu $0.2557>0.0314$. Artinya terdapat peningkatan soft skill siswa siswa grup eksperimen dan grup kontrol.

\section{PENDAHULUAN}

Sesuai amanat Undang-undang Nomor 20 tahun 2003, bahwa sedianya pendidikan dapat menjadi sarana, yaitu sebagai jembatan dalam membentuk kepribadian peserta didik agar menjadi lebih baik. Secara rinci, dalam undang-undang ini menjelaskan, bahwa bukan hanya kecerdasan yang menjadi tujuan pembelajaran namun juga nilai spiritual, pengendalian diri, kepribadian dan juga ketrampilan. Tentu saja ini bukan hal mudah. Menjadi sangat penting, bahwa guru harus selalu mengutamakan proses pembentukkan dari tagihan-tagihan indicator tersebut. Salah satunya adalah melalui proses pembelajaran yang bermutu.

Proses pembelajaaran yang terencana dengan baik dan matang, tentunya akan berakibat minim kesalahan. Proses perencanaan pembelajaran dapat dilakukan dengan memilih metode pembelajaran yang tepat. Metode dipilih agar membentuk dua hal utama yang menjadi tujuan belajar, yaitu keterampilan Hard Skill dan Soft Skill. Keduanya haruslah berimbang dan saling melengkapi agar tujuan belajar dapat terwujud secara maksimal.

Pada pembelajaran matematika, hard skill dan soft skill sangat penting. Hard skill merupakan penguasaan ilmu pengetahuan, teknologi, dan keterampilan teknis yang berhubungan dengan bidang ilmunya. Hard skill matematis siswa diturunkan dari kompetensi inti dan kompetensi dasar matematika pada tingkat kelas yang bersangkutan. Sedangkan untuk soft skill matematis siswa adalah keterampilan seseorang ketika berhubungan dengan orang lain (interpersonal skills) dan keterampilan dalam mengatur dirinya sendiri (intrapersonal skills) yang mampu mengembangkan kerja secara maksimal. Dapat dikatakan, soft skill adalah kecakapan yang dimiliki seseorang untuk berani menghadapi masalah hidup kemudian 
secara proaktif dan kreatif mencari serta menemukan solusi sehingga mampu untuk mengatasinya. Hal ini sejalan dengan Putri (2019), yang berpendapat bahwa siswa yang menguasai hard dan soft skill akan dapat mengembangkan dan meningkatkan potensi SDM dalam menunjang kesiapan kerja.

Mengingat pentingnya soft skill, maka kemampuan ini perlu sekali ditingkatkan. Pelatihan soft skill dapat memperbaiki potensi seseorang, membuat tenaga kerja lebih fleksible, memiliki sikap positip untuk mudah berubah, mampu menangani berbagai perubahan tuntutan kerja dan lebih kompetitif (Rani, 2010:4).

Begitu penting peranan soft skill juga diungkapkan oleh Klause (2008). Menurutnya, soft skills merupakan komplemen hard skills yang sangat diperlukan dalam dunia kerja, Soft skill ini bersifat non teknis, intangible, dan tidak mudah dalam mengajarkan. Senada dengan Moma (2015) yang menjelaskan bahwa kesuksesan seseorang tidak semata-mata ditentukan oleh penguasaan ilmu pengetahuan.

Penguasaan ilmu pengetahuan umumnya melalui tahap pengetahuan (knowing), acting, menuju kebiasaan (habit). Jelas sekali bahwa soft skill tidak sebatas hanya pada pengetahuan saja. Perlu tahapan mengajarkan soft skill, berupa karakter agar siswa mampu memahami, merasakan, dan mengerjakan sekaligus nilai-nilai kebajikan (Haryati, 2014).

Mampu mengelola diri dan juga orang lain adalah bagian dari soft skill. Dalam proses pembelajaran hal ini menjadi unsur penunjang dimana siswa tidak bersifat indivual, mengerjakan segala hal sendiri meskipun termasuk siswa mampu dan pintar.

Seorang guru harus mampu mengembangkan karakter siswa. Hal tersebut dapat dimulai dengan merencanakan tahapan pembelajaran. Tahapan pembelajaran dapat dipilih sesuai dengan kebutuhan.

Dalam keberhasilan pembelajaran matematika. Soft skill amerupakan salah satu unsur yang sangat penting untuk dikuasai. Elfindri (2011) menyebutkan, bahwa sudah saatnya proses pendidikan dari nilai-nilai universal di sekolah melalui integrasi aspek soft skills ke dalam sebagian besar mata ajar yang diberikan. Kenyataan bahwa siswa dengan soft skill yang tinggi cenderung belajar lebih aktif dan mampu mengatur waktu belajar secara efisien. Artinya, soft skill adalah penyeimbang yang sangat diperlukan dalam pembelajaran. Sumarmo (2015) mengemukakan beberapa jenis soft skills matematis antara lain: disposisi matematis, kemandirian belajar (self-regulator learning), self-efficacy, selfesteem, self-concept, self-confidence, habits of mind, pendidikan nilai, budaya, dan 
karakter serta pandangan siswa terhadap pembelajaran matematika.

Berdasarkan pengamatan di sebuah MTs, masih banyak guru yang mengutamakan peningkatan hard skill dalam pembelajaran matematika. Kebijakan pembelajaran dengan online (dalam jaringan/daring) semakin menyulitkan peningkatan soft skill. Beberapa alasannya adalah masa pandemic dan beban materi matematika yang cukup berat. Di masa pandemic, peningkatan hasil kognitif juga sudah merupakan prestasi yang membanggakan. Berdasarkan pengamatan, guru telah banyak mencoba metode dan media untuk meningkatkan hard skill. Soft skill rata-rata merupakan tujuan sisipan yang diperoleh sekaligus dalam pembelajaran.

Aspek soft skill seperti berpikir logis, keaktifan belajar, kerjasama tim, rasa percaya diri, berani mengambil resiko, toleransi, etika morak, dan kemampuan menejemen perlu ditingkatkan guna menunjang hasil kognitif dalam belajar matematika. Pemberian materi melalui Google Classroom dirasakan tidak maksimal. Oleh karena itu, perlu mendesain suatu pembelajaran online yang memodifikasi jalannya pembelajaran menjadi tidak sekedar membaca materi atau menonton video. Pembelajaran dipaketkan dengan pendekatan kontekstual dalam kemasan pembelajaran generative. Intisari dari belajar generatif adalah bahwa otak tidak menerima informasi dengan pasif, melainkan justru dengan aktif mengkonstruk suatu interpretasi dari informasi tersebut dan kemudian membuat kesimpulan. Pengetahuan dibangun oleh siswa sedikit demi sedikit, yang hasilnya diperluas melalui konteks yang terbatas. Tahapan dalam pembelajaran generative adalah: 1) tahap orientasi, 2) tahap pengungkapan ide, 3) tahap tantangan dan restrukturisasi, 4) tahap penerapan, dan 5) tahap melihat kembali.

Jalannya pembelajaran tidak semua disampaikan oleh guru. Siswa harus mengkonstruksi sendiri pengetahuan di benak mereka tentang pengetahuan yang lama dan yang baru diperoleh. Dengan dasar itu pembelajaran harus dikemas menjadi proses 'mengkonstruksi' bukan 'menerima' pengetahuan (Zulkarnain, 2014)

Aspek kontektual memudahkan siswa melogika sutau permasalahan matematika. Shoimin (2014) membagi pembelajaran kontekstual ke dalam kegiatan awal, inti dan akhir. Rangkaian dalam kegiatan berisi aktivitas siswa dengan bantuan petunjuk guru, membaca materi, mengerjakan LKS dan berdiskusi secara virtual. Lebih lanjut, Elaine mengatakan bahwa pendekatan kontekstual adalah suatu sistem pembelajaran yang cocok dengan otak yang menghasilkan makna dengan menghubungkan muatan akademis dengan konteks dari kehidupan sehari-hari peserta didik (Putra, 2017). 
Dengan generative, siswa memperoleh kesempatan berdiskusi meskipun online. Pembelajaran generative yang menekankan pada pengintegrasian antara pengetahuan yang telah dimiliki sebelumnya dengan pengetahuan baru, sangat berpotensi dalam meningkatkan soft skill siswa.

\section{METODE}

Jenis penelitian ini adalah kuantitafif dengan Quasi eksperiment. Karena diberikan dengan berbasis online, peneliti membuat dua grup Whatsapp, Grup pertama adalah grup eksperimen, yaitu kelompok siswa yang pembelajarannya menggunakan model pembelajaran generatif dengan pendekatan kontekstual. Grup kedua adalah kelompok kontrol, yaitu kelompok siswa yang pembelajarannya menggunakan pembelajaran konvensional. Anggota grup adalah anggota kelas yang sudah terbentuk sebelumnya, sehingga tidak dilakukan lagi pengelompokkan secara acak terhadap siswa. Cara ini dipilih dengan harapan tidak mengganggu siswa di pelajaran yang lainnya.

Populasi dalam penelitian ini adalah siswa kelas VIII MTs Insan Kreasi pada semester ganjil tahun pelajaran 2020/2021 yang berjumlah 95 siswa. Untuk mengisi grup whatsaap, anggota grup eksperimen sebanyak 34 siswa dan grup kontrol sebanyak 31 siswa.
Instrumen yang dipergunakan untuk mengetahui peningkatan soft skill berupa angket. Sebelum dipergunakan, angket terlebih dahulu divalidasi dengan penilaian pakar. Angket diberikan kepada kedua kelompok sebelum dan setelah pemberlakuan treatment. Angket yang diberikan sebelum treatment/pretest dan setelah treatment/postes merupakan angket yang serupa.

Teknik pengumpulan data yang dipergunakan berupa angket. Selanjutnya, setelah data angket diperoleh, dilanjutkan dengan analisis data. Analisi data yang digunakan yaitu statistika deskriptif, pengujian prasyarat data yang meliputi uji normalitas, uji homogenitas, uji-t, dan uji analisis gain.

Berikut ini adalah indikator soft skill yang dipergunakan.

Tabel 1. Indikator Soft Skill

\begin{tabular}{|c|l|}
\hline Variabel & \multicolumn{1}{|c|}{ Indikator } \\
\hline Soft skill & Keaktifan belajar \\
\cline { 2 - 3 } & Kerjasama Tim \\
\cline { 2 - 2 } & Rasa percaya diri \\
\cline { 2 - 2 } & Berani mengambil resiko \\
\cline { 2 - 2 } & Toleransi \\
\cline { 2 - 2 } & Etika moral \\
\cline { 2 - 2 } & Kemampuan manajemen \\
\hline
\end{tabular}

Pasangan hipotesis peningkatan soft skill yang dipergunakan adalah:

$H_{0}: \mu_{1} \leq \mu_{2}$

$H_{1}: \mu_{1}>\mu_{2}$ 
Dengan $\mu_{1}$ : Nilai rata-rata soft skill siswa grup eksperimen dan $\mu_{2}$ : Nilai ratarata soft skill siswa grup kontrol.

Selanjutnya, untuk keperluan pelaksanaan penelitian, peneliti juga menyiapkan Rencana Pelaksanaan Pembelajaran (RPP) untuk kedua grup.

\section{HASIL DAN PEMBAHASAN}

\section{Data Pretes}

Berdasarkan hasil analisi pretes, diperoleh data sebagai berikut:

Tabel 2. Statistik Deskriptif Data Pretes

\begin{tabular}{|l|l|l|l|l|l|l|}
\hline Grup & $\mathrm{n}$ & Mean & Me & Mo & Var & Sb \\
\hline I & 34 & 68,13 & 68,73 & 70,3 & 49,06 & 7,00 \\
\hline II & 31 & 67,11 & 67,1 & 60,9 & 54,89 & 7,06 \\
\hline
\end{tabular}

Keterangan:

I. Grup Eksperimen

II. Grup kontrol

Mean=rata-rata

$\mathrm{Me}=$ median

Mo $=$ modus

Var = varian

$\mathrm{Sb}=$ Simpangan baku

Setelah perhitungan deskripsi data, selanjutnya analisis data dilanjutkan dengan menghitung normalitas, homogenitas, dan uji perbedaan soft skill siswa. Uji normalitas menggunakan chi kuadrat, uji homogenitas menggunakan uji fisher, dan uji perbedaan menggunakan t. Hasil data pretes sebagai berikut.
Tabel 3. Hasil Persyaratan Data Pretes

\begin{tabular}{|l|l|l|l|}
\hline Ket & $\begin{array}{l}\text { Nilai } \\
\text { hitung }\end{array}$ & $\begin{array}{l}\text { Nilai } \\
\text { Tabel }\end{array}$ & $\begin{array}{l}\text { Kesim- } \\
\text { pulan }\end{array}$ \\
\hline $\begin{array}{l}\text { Normalitas } \\
\text { Grup I }\end{array}$ & 1,005 & 11.07 & $\begin{array}{l}\text { Berdistribusi } \\
\text { normal }\end{array}$ \\
\hline $\begin{array}{l}\text { Normalitas } \\
\text { Grup II }\end{array}$ & 2,069 & 11,07 & $\begin{array}{l}\text { Berdistribusi } \\
\text { normal }\end{array}$ \\
\hline $\begin{array}{l}\text { Homoge } \\
\text { nitas }\end{array}$ & 1,119 & 1,822 & Homogen \\
\hline Uji t & 0,679 & 1,669 & Ho diterima \\
\hline
\end{tabular}

Penelitian dilakukan pada taraf signifikan $\alpha=0,05$, Hasil Pada uji perbedaan, Ho diterima. Artinya tidak terdapat perbedaan soft skil siswa antara grup eksperimen dan grup kontrol sebelum diberikan perlakuan.

\section{Data Postes}

Berdasarkan hasil analisi postes, diperoleh data sebagai berikut:

Tabel 4. Statistik Deskriptif Data Postes

\begin{tabular}{|l|l|l|l|l|l|l|}
\hline Grup & $\mathrm{n}$ & Mean & Me & Mo & Var & Sb \\
\hline I & 34 & 76,31 & 73,4 & 100 & 175.97 & 13,27 \\
\hline II & 31 & 68,37 & 67,1 & 65,5 & 92,62 & 9,62 \\
\hline
\end{tabular}

Keterangan:

I. Grup Eksperimen

II. Grup kontrol

Mean=rata-rata

$\mathrm{Me}=$ median

Mo $=$ modus

Var $=$ varian

$\mathrm{Sb}=$ Simpangan baku 
Sama halnya dengan cara menganalisis data pretes, setelah perhitungan deskripsi data, selanjutnya analisis data postes dilanjutkan dengan menghitung normalitas, homogenitas, dan uji perbedaan soft skill siswa. Uji normalitas menggunakan chi kuadrat, uji homogenitas menggunakan uji fisher, dan uji perbedaan menggunakan t. Hasil data postes sebagai berikut:.

Tabel 5. Hasil Persyaratan Data Postes

\begin{tabular}{|l|l|l|l|}
\hline Ket & $\begin{array}{l}\text { Nilai } \\
\text { hitun } \\
\mathrm{g}\end{array}$ & $\begin{array}{l}\text { Nilai } \\
\text { Tabe } \\
\mathrm{I}\end{array}$ & $\begin{array}{l}\text { Kesim- } \\
\text { pulan }\end{array}$ \\
\hline $\begin{array}{l}\text { Normalita } \\
\text { s } \\
\text { Grup I }\end{array}$ & 9,819 & $\begin{array}{l}11.0 \\
7\end{array}$ & $\begin{array}{l}\text { Berdistribus } \\
\text { i normal }\end{array}$ \\
\hline $\begin{array}{l}\text { Normalita } \\
\text { s Grup II }\end{array}$ & 7,826 & $\begin{array}{l}11,0 \\
7\end{array}$ & $\begin{array}{l}\text { Berdistribus } \\
\text { i normal }\end{array}$ \\
\hline $\begin{array}{l}\text { Homoge } \\
\text { nitas }\end{array}$ & 0,52 & 1,82 & Homogen \\
\hline Uji t & 6 & 2 & \\
\hline
\end{tabular}

Penelitian dilakukan pada taraf signifikan $\alpha=0,05$, Pada uji perbedaan, Ho ditolak. Artinya terdapat perbedaan soft skil siswa antara grup eksperimen dan grup kontrol setelah diberikan perlakuan.

\section{Data Peningkatan}

Untuk keperluan menjawab rumusan apakah terdapat perbedaan peningkatan, selanjutnya dilakukan pengujian analisis 96 gain. Diperoleh hasil bahwa grup eksperimen $>$ grup kontrol $(0.2557>0.0314)$. Hal ini menunjukkan bahwa terdapat peningkatan soft skill siswa pada siswa yang diberi model pembelajaran generatif dengan pendekatan kontekstual dan juga pada grup control.

Kedua kelompok sama-sama mengalami peningkatan. Hanya saja,, jika dil ihat dari nilai rata-rata, peningkatan grup eksperimen lebih tinggi dari grup control.

Tabel 6. Rata-rata Nilai Postes

\begin{tabular}{|l|l|l|l|}
\hline $\begin{array}{l}\text { Keteranga } \\
\mathrm{n}\end{array}$ & $\begin{array}{l}\text { Prete } \\
\mathrm{s}\end{array}$ & $\begin{array}{l}\text { Poste } \\
\mathrm{s}\end{array}$ & $\begin{array}{l}\text { Peningkata } \\
\mathrm{n}\end{array}$ \\
\hline Grup I & 68,13 & 76,31 & 8,18 \\
\hline Grup II & 67,11 & 68,37 & 1,26 \\
\hline
\end{tabular}

\section{Pembahasan}

Pada saat belum diberikan pembelajaran, soft skill kedua grup tidak terdapat perbedaan. Namun setelah diberikan pembelajaran, sesuai dengan data postes terlihat bahwa kedua kelas memiliki perbedaan soft skill. Berdasarkan data gain, terbukti terdapat peningkatan soft skill.

Kondisi ini terjadi karena treatment pada grup eksperimen. Yaitu diberikan model pembelajaran generatif dengan pendekatan kontekstual, yang mana pembelajaran berpusat pada siswa, guru hanya sebagai fasilitator yang membimbing proses pembelajaran, melatih siswa untuk menyelesaikan permasalahan secara berkelompok. Metode yang diterapkan juga 
memberikan kebebasan kepada siswa untuk mengungkapkan ide atau gagasan dan alasan terhadap permasalahan yang diberikan. Dengan demikian siswa lebih memahami pengetahuan yang diperoleh.

Dalam proses pembelajarannya yang berbasis daring kedua grup diberikan materi yang sama namun dalam kemasan berbeda. Perbedaan terletak pada perintah dan tahapan sesuai dengan model pembelajaran yang digunakan. Di dalam bahan ajar terdapat Lembar Kerja Siswa (LKS) yang harus di jawab oleh siswa pada setiap pertemuannya.

Isilah soal-soal yang ada dibawah ini dengan benar!

1. Diketahui barisan bilangan $1,4,7,10,13, \ldots$

Suku ke- -40 barisan tersebut adalah ..

2. Diketahui barisan aritmetika $15,20,25,30,35, \ldots$

a. Tentukan rumus suku ke-n dari barisan tersebut!

b. Tentukan sulu ke-11 dari barisan tersebut!

3. Sebuah gedung bioskop, banyaknya kursi pada barisan paling depan adalah 15 buah, banyaknya kursi pada baris di belakangnya selalu lebih 3 buah dari baris didepannya. Berapa banyak kursi pada baris ke-12 dari

Gambar 1. Contoh LKS grup II

Pada gambar 1. Adalah contoh salah satu lembar kerja siswa di grup control Perintah menggunakan bahasa biasa. Isilah sosl-soal yang ada di bawah ini dengan benar!".
Petunjuk kerja

1. Bergabunglah dengan kelompolmu!

2. Diskusikan jawaban dari persoalan matematika di bawah ini!

3. Ungkapkan jawabanmu jika ternyata jawabnmu tidak sama dengan teman sekelompolmu!

4. Dengarkan alasan teman sekoleompokmu jika ada yang menyanggah jawabanmu!

5. Selamat bekerja Tim!

Selesaikan permasalahan matematika berikut ini!

1. Diketahui barisan bilangan $1,4,7,10,13, \ldots$

Suku ke- 40 barisan tersebut adalah ...

2. Diketahui barisan aritmetika $15,20,25,30,35, \ldots$

a. Tentukan numus suku ke-n dari barisan tersebut!

b. Tentukan suku ke-11 dari barisan tersebut!

\section{Gambar 2. Contoh LKS grup I}

Pada gambar 2, adalah contoh salah satu lembar kerja siswa di grup eksperimen. LKS dilengkapi dengan petunjuk kerja yang digunakan sebagai sarana meningkatkan soft skill siswa. Pada petunjuk nomor 1 dan 2, siswa diperintahkan untuk berkelompok dan berdiskusi. Ini dipergunakan untuk soft skill kerja tim. Petunjuk nomor 3, siswa diminta untuk berpendapat, dan nomor 4, siswa di latih untuk mendengarkan dan toleransi.

Pada pertemuan awal terdapat kendala yaitu siswa masih bingung untuk memahami materi serta tugas yang diberikan. Namun selanjutnya kendala tersebut dapat diatasi. Cara kerja berkelompok dengan cara online masih terkendala. Peneliti memberikan waktu 10 menit untuk mengisi Lembar kerja dengan cara siswa berkomunikasi melalui 
Whatsapp. Untuk berpendapat, siswa bisa saling memfoto jawabnnya dan berbicara melalui voice.

Berbeda dengan pertemuan di grup kontrol yang menggunakan pembelajaran konvensional. Meskipun ini metode biasa, penyampaian secara daring tetap tidak seperti biasa tatap muka di kelas. Selain mengirmkan bahan ajar, peneliti juga mengirim video pembelajaran

Berdasarkan uraian di atas terlihat bahwa siswa yang diajarkan dengan model pembelajaran generatif dengan pendekatan kontekstual terdapat peningkatan soft skill yang lebih baik dibandingkan dengan siswa yang diajarkan dengan model pembelajaran konvensional. Hal tersebut juga sejalan dengan penelitian yang dilakukan La Moma (2015). hasil penelitiannya menyatakan bahwa hasil yang diperoleh dari penelitian ini adalah hasil analisis data ditemukan bahwa terdapat perbedaan pencapaian, peningkatan soft skills siswa antara kelas eksperimen dan kelas kontrol. Dengan demikian, siswa yang diajarkan dengan model pembelajaran generatif dengan pendekatan kontekstual yang diterapkan dalam proses pembelajaran dapat memberikan peningkatan terhadap soft skill yang dimiliki oleh siswa.

Sejalan dengan Nealy (2005), yang meneliti tentang integrasi soft skills melalui pembelajaran aktif menemukan bahwa pembelajaran aktif telah menumbuhkan soft 98 skills dan skills lainnya yang diperlukan untuk meningkatkan performa kerja di era abad 21 ini. Penelitian ini menguatkan bahwa pembelajaran soft skills menekankan pengalaman belajar yang melibatkan fisik, mental dan psychis siswa serta kemandirian belajar.

Selain itu, efektifitas kontekstual juga sejalan dengan penelitian Intan dkk (2017). Hasil penelitian menunjukan :terdapat perbedaan kemampuan penalaran matematis siswa antara yang mendapat pendekatan pembelajaran CTL dan yang mendapat pembelajaran konvensional, serta terdapat peningkatan kemampuan penalaran matematis siswa yang mendapat pendekatan pembelajaran CTL.

\section{PENUTUP}

\section{Simpulan}

Pembelajaran generative dengan pendekatan kontekstual terbukti dapat meningkatkan soft skill siswa.

\section{Saran}

Guru harus memodifikasi pemberian materi di masa pandemic ini. Meskipun telah ada kesepakan dari pihak lembaga/sekolah menggunakan Google classroom, namun perlu sekali pengontrolan dan pemantauan langsung, sehingga guru dapat memastikan bahwa siswa benar-benar mencapai indikator yang ditargetkan dengan berusaha sendiri. Model pembelajaran generative learning dengan pendekatan kontekstual 
dapat digunakan sebagai altrenatif pembelajatran dalam rangkaian pembelajaran daring..

\section{DAFTAR PUSTAKA}

Elfindri, dkk. 2011. Soft Skills untuk Pendidik. Jakarta: Baduose Media. E.S.

Haryati, \& Sudrajat. (2014). Model Pembelajaran Project Citizen Pada Mata Pelajaran Pendidikan Pancasila Dan Kewarganegaraan Dalam Membentuk Karakter Peserta Didik Sebagai Warga Negara Yang Baik. Prosiding Seminar Nasional dan Bedah Buku Pendidikan Karakter dalam Implementasi Kurikulum 2013

Klause,P. (tth). The hard truth about soft skills. Diunduh dari http://www.peggyklos.com pada 20 Mei 2020

Moma, L. 2015. Peningkatan soft skill siswa SMP melalui pembelajran generatif. Cakrawala Pendidikan, Th. XXXIV, No. 2

Nealy,C. (2005). Integrating soft skills Through active learning in the management classroom. Journal of Collage teaching \& learning. Vol 2 number 4. April 2005.

Putra, G.P. 2017. Eksperimentasi

Pendekatan Kontekstual Berbantuan Hands On Activity (HoA) Terhadap Kemampuan Pemecahan Masalah Matematik. Al-Jabar: Jurnal Pendidikan
Matematika Vol. 8, No. 1, 2017, Hal 73 80

Putri., YE. Dkk 2019. Peningkatan Kualitas Hard Skill dan Soft Skill Melalui Pengembangan Program Teaching Factory (TEFA) di SMK Model PGRI 1 Mejayan. Jurnal Pendidikan Ekonomi UM Metro. Vol 7 No 2 Hal 26-33

Rani, E.M.S. (2010). Need and importance of soft skills in student. Vol,-II 3 JanuariJuni (Summer) 2010. Associate Professor in English, Sri Sarada College for Women, Salem- 636016

Sari, I.P, dkk. 2017. Pengaruh pendekatan Contextual Teaching and Learning (CTL) terhadap kemampuan penalaran matematis siswa. Prima: Jurnal Pendidikan Matematika Vol. 1, No. 1, Juli 2017, hal. 19-32 P-ISSN: 2579-9827, EISSN: $2580-2216$

Shoimin, A. 2014. 68 model pembelajaran inovatif dalam kurikulum 2013. Yogyakarta: Ar-ruzz media

Sumarno, U. dkk. 2017. Hard Skill dan Soft Skill Matematik Siswa. Bandung. Riefka Aditama

Zulkarnain, I \& Agustini Rahmawati. 2014. Model pembelajaran generatif untuk mengembangkan penalaran matematis siswa. EDU-MAT Jurnal Pendidikan Matematika, Volume 2, Nomor 1, hlm 8 14. 